\title{
Perencanaan Instalasi Pengolahan Air Minum di Kecamatan Segedong, Kalimantan Barat dalam Rangka Pemenuhan Target SDGs
}

\author{
Astisza Syahla Ludmilla Parabi ${ }^{1 *}$, Kiki Prio Utomo ${ }^{2}$, Laili Fitria ${ }^{3}$ \\ 1,2,3 Environmental Engineering Department, Universitas Tanjungpura, Pontianak \\ *Koresponden email: astiszasyahla@gmail.com
}

Diterima: 7 Desember 2021

Disetujui: 18 Januari 2022

\begin{abstract}
Drinking water is an aspect of Sustainable Development Goals/SDGs 2030 with the aim of ensuring the availability and management of clean water and sustainable sanitation. Many efforts to fulfill drinking water have been carried out by the Government of Indonesia, including in Segedong District as evidenced by the existence of a Drinking Water Treatment Plant. However, with the increase in population, the water produced by the WTP cannot sufficient of drinking water needs, so it is necessary to increase the amount of drinking water by planning a Water Treatment Plant for Segedong District for 15 years (2021-2035). The method used is primary data collection (climatological data) and secondary data (population and public facilities) which will then be processed to obtain the amount of drinking water needed and the required WTP capacity. The results obtained that the raw water source comes from the Peniti River, where the Peniti River has parameters that exceed the quality standard, namely color, $\mathrm{pH}$, turbidity, organic matter, manganese, iron, and total coliform. Parameters will be processed with coagulation, flocculation, sedimentation, filtration, disinfection, neutralization. The calculation results show the amount of drinking water needed is $85.56 \mathrm{l} / \mathrm{sec}$. Planning is carried out in 3 stages every 5 years, so that the planning to be carried out is phase I planning for drinking water needs in 2026 with a capacity of 75 1/s. Phase I planning requires an area of $293.97 \mathrm{~m}^{2}$.
\end{abstract}

Keywords: drinking water, segedong district, treatment capacity, water needs, WTP planning

\begin{abstract}
Abstrak
Air minum merupakan salah satu aspek dari Sustainable Development Goals/SDGs 2030 dengan tujuan untuk menjamin ketersediaan dan pengelolaan air bersih dan sanitasi yang berkelanjutan. Berbagai upaya pemenuhan air minum telah dilakukan oleh pemerintah Indonesia, termasuk di Kecamatan Segedong yang dibuktikan dengan adanya Instalasi Pengolahan Air Minum. Namun dengan bertambahnya jumlah penduduk, air yang dihasilkan IPA tidak dapat mencukupi kebutuhan air minum, sehingga perlu dilakukan penambahan jumlah air minum dengan merencanakan Instalasi Pengolahan Air (IPA) Minum Kecamatan Segedong selama 15 tahun (2021-2035). Metode yang digunakan adalah pengumpulan data primer (data klimatologi) dan data sekunder (penduduk dan fasilitas umum) yang selanjutnya akan diolah untuk mendapatkan jumlah kebutuhan air minum dan kapasitas IPA yang dibutuhkan. Hasil yang diperoleh bahwa sumber air baku berasal dari Sungai Peniti, dimana Sungai Peniti memiliki parameter yang melebihi baku mutu yaitu warna, $\mathrm{pH}$, kekeruhan, bahan organik, mangan, besi, dan total coliform. Proses pengolahan air terdiri dari koagulasi, flokulasi, sedimentasi, filtrasi, desinfeksi, netralisasi. Hasil perhitungan menunjukkan jumlah kebutuhan air minum sebesar 85,56 1/dt. Perencanaan dilakukan 3 tahap setiap 5 tahun sekali, sehingga perencanaan yang akan dilakukan adalah perencanaan kebutuhan air minum tahap I tahun 2026 dengan kapasitas 75 1/dt. Perencanaan tahap I membutuhkan lahan seluas 293,97 m².
\end{abstract}

Kata Kunci: air minum, kapasitas pengolahan, kebutuhan air, kecamatan segedong, perencanaan IPA

\section{Pendahuluan}

Air minum menjadi tujuan utama pada pembangunan berkelanjutan (Sustainable Development Goals/ SDGs) dengan tujuan utama untuk menjamin ketersediaan dan pengelolaan air bersih dan sanitasi yang berkelanjutan bagi semua. Adanya target dari pembangunan berkelanjutan pada tahun 2030, memastikan pengambilan dan suplai air bersih yang berkelanjutan untuk mengatasi kelangkaan air dan secara substansial mengurangi jumlah orang yang mengalami kelangkaan air, maka diperlukan upaya untuk menyediakan air minum yang layak serta memiliki jumlah yang cukup untuk digunakan seluruh makhluk hidup, terutama manusia. 
Upaya penyediaan air minum telah dilakukan oleh pemerintah di Indonesia termasuk di Kecamatan Segedong yang dibuktikan dengan adanya Instalasi Pengolahan Air Minum (IPA Minum) di daerah tersebut. IPA Minum Kecamatan Segedong dibangun pada tahun 2010 yang hingga saat ini masih terus beroperasi dengan kapasitas $10 \mathrm{lt} / \mathrm{dt}$. Namun, IPA tersebut memiliki beberapa kendala yang cukup mempengaruhi kualitas air yang dihasilkan seperti penggunaan dosis koagulan yang jumlahnya tidak sesuai dengan jumlah air yang diolah, bak sedimentasi dan bak filtrasi yang mengalami overflow, bahan filter yang tidak dilakukan pembersihan secara rutin, serta bak filtrasi yang berlubang, yang menyebabkan air hasil olahan kurang optimal. Permasalahan-permasalahan tersebut menjadi latar belakang dalam perencanaan baru IPA Kecamatan Segedong dengan waktu perencanaan hingga 15 tahun yang akan datang (2021-2035) agar dapat memenuhi tujuan dari pembangunan berkelanjutan khususnya untuk air dan sanitasi di Kecamatan Segedong, Kabupaten Mempawah, Kalimantan Barat.

Maksud dan tujuan perencanaan IPA ini yaitu untuk menghitung kebutuhan air minum di Kecamatan Segedong hingga 15 tahun yang akan datang (2021-2035) dan menghitung volume bangunan intake, IPA, dan reservoir sesuai dengan jumlah kebutuhan air minum yang telah didapatkan. Adanya perencanaan IPA Kecamatan Segedong ini diharapkan memberi manfaat bagi masyarakat yaitu dapat dijadikan pedoman/ referensi bagi pemerintah dalam pembangunan maupun pengembangan IPA.

\section{Metode Perencanaan}

\section{Lokasi Perencanaan IPA}

Lokasi untuk perencanaan Instalasi Pengolahan Air Bersih ini terletak di Kecamatan Segedong, Kabupaten Mempawah, Kalimantan Barat yang terletak diantara 00 03'20" Lintang Utara dan 109 08'20" Bujur Timur dan $109^{\circ} 21^{\prime} 40^{\prime \prime}$ Bujur Timur. Luas wilayah Kecamatan Segedong sebesar 164,00 km2 atau sekitar 12,84\% dari luas wilayah Kabupaten Mempawah. Daerah Pemerintahan Segedong terdiri dari 6 desa, 22 dusun, 42 RW, dan 136 RT[3].

Air bersih yang digunakan penduduk untuk memenuhi berbagai aktivitas sehari-hari seperti untuk mandi, mencuci, dan sanitasi. Sumber air bersih pada Kecamatan Segedong bersumber dari sungai, danau, atau air hujan. Namun, sebagian di daerah tersebut air bersih dikelola untuk komoditas industri oleh PDAM setempat. Kecamatan Segedong hanya memiliki 1 DAS yang terbentang sepanjang daerah tersebut. DAS Peniti memiliki luas $\pm 29.503,6 \mathrm{Ha}$ [3].

Permasalahan Air Minum di Kecamatan Segedong

Masyarakat Kecamatan Segedong dalam memenuhi kebutuhan air menggunakan air hujan dan juga air PDAM. Air hujan digunakan sebagai air minum dan untuk memasak, yang akan tampung dalam wadah. Kecamatan Segedong ini juga memiliki Instalasi Pengolahan Air sudah beroperasi sejak tahun 2010 hingga saat ini. Namun, tidak semua masyarakat dapat air PDAM karena IPA Segedong ini memiliki kapasitas kecil, sehingga tidak dapat memenuhi kebutuhan air masyarakat yang biasanya air hasil IPA ini digunakan untuk air bersih (mandi, cuci, kakus, dll). Masyarakat yang belum mendapatkan air bersih dari PDAM ini, biasanya menampung air hujan atau mengambil air langsung ke sungai. Sungai yang ada di kecamatan ini adalah Sungai Peniti.

\section{Metode Perencanaan}

Perencanaan terdiri dari 2 tahap yaitu pengumpulan dan pengolahan data. Pengumpulan data berupa data primer (pengambilan sampel air baku, perhitungan debit air permukaan, dan penentuan titik sampling \& luas penampang basah) dan data sekunder (jumlah penduduk Kecamatan Segedong 2016-2020, fasilitas umum Kecamatan Segedong 2015-2019, dan data klimatologi Kecamatan Segedong 2011-2020).

Pengolahan data primer dan sekunder terdiri dari:

1. Hasil pengujian terhadap sampel air baku.

2. Analisis ketersediaan air baku.

3. Perhitungan proyeksi penduduk \& kebutuhan air minum.

4. Penentuan perhitungan bangunan intake IPA dan reservoir

\section{Hasil dan Pembahasan}

Perencanaan IPA untuk Kecamatan Segedong terletak di hulu Sungai Peniti dengan jarak $\pm 2 \mathrm{~km}$ dari daerah awal pelayanan. Pembangunan intake terletak di pinggir sungai dengan jarak $50 \mathrm{~m}$ ke bangunan IPA. Bangunan IPA yang direncanakan menggunakan pondasi berupa plat beton dan bangunan IPA berbahan dasar baja. Daerah pelayanan digambarkan dengan warna hijau, dimana daerah tersebut merupakan jalan utama menuju Instalasi Pengolahan Air Minum untuk Kecamatan Segedong. Daerah yang dilayani sepanjang $\pm 11 \mathrm{~km}$ dari bangunan IPA seperti terlihat pada Gambar 1. 


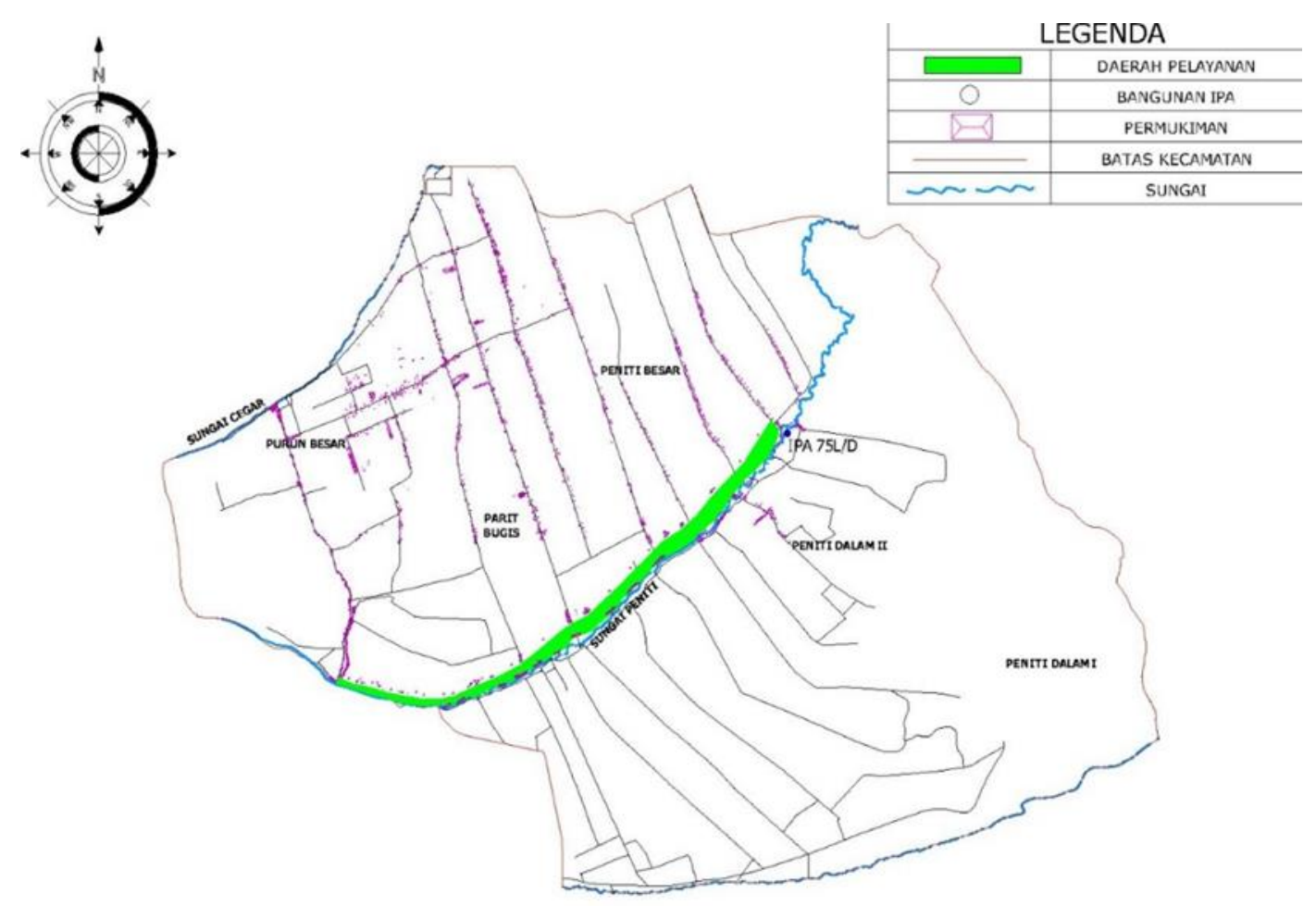

Gambar 1. Daerah pelayanan instalasi Pengolahan Air Minum Kecamatan Segedong Sumber: Disdukcapil Kabupaten Mempawah, 2021

\section{Hasil Uji Kualitas Air}

Hasil uji air Sungai Peniti yang dikomparasikan dengan Peraturan Menteri Kesehatan No. 492 Tahun 2010 tentang Persyaratan Kualitas Air Minum

Tabel 1. Hasil uji kualitas air Sungai Peniti

\begin{tabular}{|c|c|c|c|c|}
\hline No. & Parameter Uji & Satuan & Hasil Uji & Kadar maksimum* \\
\hline \multicolumn{5}{|c|}{ Parameter Fisik } \\
\hline 1. & Suhu & ${ }^{\circ} \mathrm{C}$ & 23,0 & Suhu Udara $\pm 3^{\circ} \mathrm{C}$ \\
\hline 2. & Warna & Unit Pt-Co & 192 & 15 \\
\hline 3. & $\mathrm{Bau}$ & - & Tidak Berbau & Tidak Berbau \\
\hline 4. & $\mathrm{pH}$ & - & 3,8 & $6,5-8,5$ \\
\hline 5. & Rasa & - & Tidak berasa & Tidak berasa \\
\hline 6. & Kekeruhan & NTU & 21,2 & 5 \\
\hline 7. & TDS & $\mathrm{mg} / \mathrm{l}$ & 72,66 & 500 \\
\hline \multicolumn{5}{|c|}{ Parameter Kimia } \\
\hline 8. & Nitrat $\left(\mathrm{NO}_{3}-\mathrm{N}\right)$ & $\mathrm{mg} / \mathrm{l}$ & 0,142 & 50 \\
\hline 9. & $\operatorname{Nitrit}\left(\mathrm{NO}_{2}-\mathrm{N}\right)$ & $\mathrm{mg} / \mathrm{l}$ & $<0,007$ & 3 \\
\hline 10. & $\begin{array}{l}\text { Zat Organik } \\
\left(\mathrm{KMnO}_{4}\right)\end{array}$ & $\mathrm{mg} / \mathrm{l}$ & 43,6 & 10 \\
\hline 11. & Sulfat $\left(\mathrm{SO}_{4}\right)$ & $\mathrm{mg} / \mathrm{l}$ & 50,9 & 250 \\
\hline 12. & $\begin{array}{l}\text { Kesadahan } \\
\left(\mathrm{CaCO}_{3}\right)\end{array}$ & $\mathrm{mg} / \mathrm{l}$ & 16,6 & 500 \\
\hline 13. & Mangan & $\mathrm{mg} / \mathrm{l}$ & 1,88 & 0,4 \\
\hline 14. & Besi (Fe) & $\mathrm{mg} / \mathrm{l}$ & 0,447 & 0,3 \\
\hline 15. & Timbal $(\mathrm{Pb})$ & $\mathrm{mg} / \mathrm{l}$ & $<0,002$ & 0,01 \\
\hline 16. & Seng $(\mathrm{Zn})$ & $\mathrm{mg} / \mathrm{l}$ & $<0,001$ & 3 \\
\hline \multicolumn{5}{|c|}{ Parameter Biologi } \\
\hline 17. & Total Coliform & Koloni/ $100 \mathrm{ml}$ & 20 & 0 \\
\hline
\end{tabular}

Berdasarkan hasil pengujian sumber air baku, terdapat beberapa parameter yang tidak sesuai dengan standar baku mutu diantaranya warna, $\mathrm{pH}$, kekeruhan, zat organik, mangan, besi, dan total coliform. Adanya zat organik $\left(\mathrm{KMnO}_{4}\right)$ dalam air sungai, menunjukkan bahwa air tersebut telah tercemar kotoran 
manusia, hewan, atau oleh sumber lain [1]. Penyebab utama adanya tingginya kadar besi yaitu rendahnya $\mathrm{pH}$ air, temperatur air, adanya gas-gas terlarut dalam air $\left(\mathrm{O}_{2}, \mathrm{CO}_{2}\right.$, dan $\left.\mathrm{H}_{2} \mathrm{~S}\right)$ [9]. Tingginya kadar total coliform disebabkan banyak penduduk yang bermukim di sepanjang pinggiran dan membuang kotoran (tinja) langsung ke sungai [13].

Tahapan Proses Pengolahan

Parameter yang melebihi baku mutu yaitu warna, $\mathrm{pH}$, kekeruhan, zat organik (KmnO4), mangan, besi, dan total coliform. Tahapan pengolahan yang dirancang dalam perencanaan ini dipilih berdasarkan pada parameter yang melebihi baku mutu sehingga pengolahan tersebut diharapkan dapat menurunkan parameter-parameter tersebut. Tahapan pengolahan yang dipilih yaitu intake - koagulasi - flokulasi sedimentasi - filtrasi - reservoir[10]. Koagulasi merupakan proses pembentukan koloid yang stabil menjadi koloid yang tidak stabil dan membentuk flok-flok dari gabungan koloid yang berbeda muatan [6]. Flokulasi adalah pengadukan lambat yang berfungsi untuk membentuk flok-flok. Sedimentasi adalah serangkaian proses pengolahan air dengan memanfaatkan gaya tarik gravitasi bumi [7]. Unit filtrasi merupakan suatu unit pengolahan dengan cara mengalirkan air melewati suatu media penyaring (filter) yang tersusun dari bahan-bahan butiran dengan diameter dan ketebalan tertentu.

Kebutuhan Air Domestik dan Non-Domestik

Kecamatan Segedong memiliki jumlah penduduk pada tahun 2021-2035 dengan rentang 27.30328.342 jiwa, sehingga Kecamatan Segedong termasuk kota kecil dengan jumlah penduduk 20.000-100.000. Kota kecil memiliki konsumsi unit sambungan rumah (SR) dengan rentang 80-120 ltr/org/hari [4]. Fasilitas umum di Kecamatan Segedong terdiri dari fasilitas pendidikan, kesehatan, dan peribadatan. Standar kebutuhan air non-domestik pada fasilitas umum, memiliki persentase 10-15\% dari kebutuhan domestik[5]. Persentase yang diambil untuk perhitungan kebutuhan air non-domestik Kecamatan Segedong sebesar 15\%. Debit pengolahan yang akan digunakan berasal dari perhitungan fluktuasi kebutuhan air yang terdiri dari debit saat normal, faktor hari maksimum, dan faktor jam puncak. Faktor hari maksimum memiliki rentang 1,15-1,25 dan untuk faktor jam puncak, sebesar 1,75 untuk kota kecil.

Tabel 2. Fluktuasi kebutuhan air Kecamatan Segedong

\begin{tabular}{cccccc}
\hline (1/dt) & Faktor & 2021 & 2026 & 2031 & 2035 \\
\hline Normal & 1 & 36,63 & 42,43 & 48,37 & 48,89 \\
Hari Maksimum & 1,15 & 42,13 & 48,79 & 55,63 & 56,22 \\
Jam Puncak & 1,75 & 64,10 & 74,25 & 84,65 & 85,56 \\
\hline
\end{tabular}

Sumber : Ditjen Cipta Karya, 2000

Perencanaan dilakukan secara bertahap, dengan asumsi bahwa setiap 5 tahun, akan dibangun IPA sesuai kebutuhan air yang telah direncanakan. Pada tahap pertama ini IPA dibangun untuk perencanaan kebutuhan air minum hingga tahun 2026. Perhitungan di atas menunjukkan pada tahun 2026, debit air minum yang dibutuhkan sebesar 74,25 1/dt atau sebesar 75 1/dt. Nilai tersebut akan menjadi debit untuk menentukan dimensi dan besarnya kapasitas pengolahan.

Perencanaan Intake, IPA, dan Reservoir

Jenis intake yang akan direncanakan pada Instalasi Pengolahan Air Minum Kecamatan Segedong adalah river intake. Kelebihan dari intake ini mudah dalam segi pemeliharaan dan baik untuk air sungai yang memiliki perbedaan level muka air saat musim hujan dan musim kemarau [12]. Bak koagulasi berbentuk persegi yang menggunakan pengadukan cepat tipe hidrolis dengan memanfaatkan gravitasi yang terjadi pada terjunan air. Bangunan koagulasi memiliki bak pembubuh koagulan berupa aluminium sulfat $\mathrm{Al}_{2}\left(\mathrm{SO}_{4}\right)_{3}$ atau tawas yang mempunyai kemampuan untuk menjernihkan air [8].

Dimensi bak koagulasi yang direncanakan sebesar:

Panjang $=1,8$ meter

Lebar $=1$ meter

Tinggi $=1,2$ meter

Sementara itu, bak flokulasi yang direncanakan menggunakan sistem gravitasi berupa saluran berbelok-belok atau baffle chanel. Dimensi bak flokulasi direncanakan berukuran:

Panjang $=4,28$ meter

Lebar $=3,5$ meter

Tinggi $=4,5$ meter 
Perencanaan IPA minum di Kecamatan Segedong memiliki 2 kompartemen yang setiap kompartemen memiliki 2 unit bak sedimentasi. Dimensi bak sedimentasi yang direncanakan sebesar:

Panjang $=15,42$ meter

Lebar $=3,5$ meter

Tinggi $=3$ meter

Jumlah minimum dari filter untuk perencanaan pengolahan kecil kurang dari $90 \mathrm{l} / \mathrm{dt}$ adalah dua sehingga dimensi bak filtrasi adalah:

Panjang $=3,8$ meter

Lebar $=1,9$ meter

Tinggi $=2$ meter

Proses desinfeksi dan netralisasi dalam perencanaan IPA Kecamatan Segedong menggunakan injeksi dozing pump berisi larutan kaporit dan kapur sebelum air hasil olahan masuk ke bak reservoir. Penggunaan kaporit ini dipilih karena mudah didapat, murah, dan dapat mereduksi (mengurangi) populasi bakteri sebanyak 90\% selama 10 detik[11]. Reservoir merupakan bangunan yang berfungsi sebagai penampung air minum hasil pengolahan. Bangunan ini berbentuk ground reservoir. Ground reservoir adalah reservoir yang sebagian besar atau seluruh reservoir tersebut terletak di bawah permukaan tanah [2]. Dimensi reservoir yang direncanakan yakni:

Panjang $=18$ meter

Lebar $=12$ meter

Tinggi $=3$ meter

\section{Kesimpulan}

Kesimpulan yang dapat diambil yaitu perencanaan ini bertujuan untuk pemenuhan kebutuhan air minum hingga tahun 2026, sehingga perencanaan bangunan IPA yang dilakukan di Kecamatan Segedong berkapasitas 75 1/dt dengan air baku bersumber dari Sungai Peniti. Hasil uji air baku menunjukkan bahwa parameter yang melebihi baku mutu terdiri dari warna, $\mathrm{pH}$, kekeruhan, zat organik $\left(\mathrm{KMnO}_{4}\right)$, mangan, besi, dan total coliform. Tahapan pengolahan air terdiri dari bangunan intake, koagulasi, flokulasi, sedimentasi, dan reservoir dengan luas wilayah yang dibutuhkan sebesar $293,97 \mathrm{~m}^{2}$.

\section{Ucapan Terima Kasih}

Penulis berterima kasih kepada dosen-dosen Jurusan Teknik Lingkungan, Universitas Tanjungpura yang telah membimbing penulis dalam perencanaan ini serta pihak-pihak yang turut berpartisipasi dalam penulisan artikel ini.

\section{Referensi}

[1] Asmadi \& Suharno. 2012. Dasar- dasar Teknologi Pengolahan Air Limbah. Yogyakarta : Gosyen Publishing.

[2] Badan Pengembangan Sumber Daya Manusia (BPSDM) PU. 2018. Modul Reservoir : Perencanaan Jaringan Pipa Transmisi dan Distribusi Air Minum.

[3] Badan Pusat Statistik. 2019. Provinsi Kalimantan Barat dalam Angka 2019. Kalimantan Barat: Badan Pusat Statistik.

[4] Direktorat Jenderal Cipta Karya. Kriteria Perencanaan Air Bersih. Ditjen Cipta Karya, Departemen Pekerjaan Umum. 2000.

[5] Direktorat Jenderal Cipta Karya. RPIJM : Buku Panduan Pengembangan Air Minum. Ditjen Cipta Karya, Departemen Pekerjaan Umum. 2007.

[6] Ermawati, Ristie \& Awaluddin Setya Aji. Sistem Penyediaan Air Minum. Magelang: Unimma Press. 2018.

[7] Febriary, Irfan. Efektivitas Aerasi, Sedimentasi, dan Filtrasi untuk Menurunkan Kekeruhan dan Kadar Besi (Fe) dalam Air. Jurnal Kesmas Indonesia. 2016.

[8] Husaini. Perbandingan Koagulan Hasil Percobaan dengan Koagulan Komersial Menggunakan Metode Jar Test. Jurnal Teknologi Mineral dan Batubara. 2018.

[9] Joko, Tri. 2010. Unit Produksi dalam Sistem Penyediaan Air Minum. Yogyakarta : Graha Ilmu.

[10] Mines, Richard O. \& Laura W. Lackey. Environmental Engineering : Principles and Practice. USA : Wiley Blackwell Publishing. 2014.

[11] Mulyani, Happy. 2017. Penulisan Praktik Analisis dan Optimasi : Sistem Penyehatan Air Minum. Yogyakarta : Pustaka Pelajar. 
[12] Pugel, Pandi M. Perencanaan Sistem Penyediaan Air Bersih di Kecamatan Belitang Kabupaten Sekadau Provinsi Kalimantan Barat. Jurnal Teknologi Lingkungan Lahan Basah. Universitas Tanjungpura Pontianak, 2015.

[13] Sasongko, Endar Budi. Kajian Kualitas Air dan Penggunaan Sumur Gali oleh Masyarakat di Sekitar Sungai Kaliyasa Kabupaten Cilacap. Jurnal Ilmu Lingkungan. Universitas Diponegoro, Semarang. 2014. 